\title{
Highs and Lows: \\ A Behavioral and Technical Analysis
}

\author{
Bruce Mizrach* and Susan Weerts \\ Department of Economics \\ Rutgers University
}

Revised: November 2007

\begin{abstract}
:
We find that turnover rises on $n$-day highs and lows and is an increasing function of $n$. We offer several explanations from the technical and behavioral finance literature for why traders might use these signals. Turnover is persistent following these events, and new lows provide abnormal returns for up to 6 trading days.
\end{abstract}

Keywords: behavioral finance; technical analysis; turnover; $n$-day high/low; abnormal returns.

JEL Classification: G14; G20.

\footnotetext{
* Corresponding author: Department of Economics, Rutgers University, New Brunswick, NJ 08901. We would like to thank the Whitcomb Center for Financial Research for providing access to the CRSP data.
} 
"Technical analysis is about as useful as going to a fortuneteller, as far as I'm concerned. There is simply no evidence that these patterns mean anything..." ${ }^{1}$ (Burton Malkiel, 2003).

\section{Introduction}

The behavioral finance literature tries to explain what motivates investors to trade. Barber and Odean (2005) emphasize that investors tend to focus on "attention grabbing" stocks. They find abnormal volume and returns attract buyers to a stock. Seasholes and Wu (2007) observe that daily price limits influence trading activity on the Shanghai stock exchange. Experiments by Das and Raghubir (2006) show that stock price trends influence perceived risk. Heath, Huddart and Lang (1999) report that when the stock price is above a one-year maximum, stock option exercise nearly doubles.

This paper provides clear evidence that technical indicators stimulate trading. We find a sharp rise in turnover as a stock crosses an $n$-day high or low and that turnover is increasing in $n$. This finding is robust to a number of controls, including market volume, returns, and news about earnings, dividends and analyst rating changes.

Our research extends Huddart, Lang and Yetman's (2007) study of 52-week highs and lows to six additional time frames: 10-day, 25-day, 50-day, 100-day, 150-day, and 200-day. We document that trading volume increases significantly whenever price exits these trading ranges. Moreover, abnormal turnover generally increases in $n$. It is also persistently abnormal for at least two weeks.

The literature does show that this trading may result in positive returns. George and Hwang (2004) found that the 52-week high is a good proxy for Jegadeesh and Titman's (1993) momentum factor. By calculating the trading imbalance and the percentage of the first time stock buyers, Seasholes and $\mathrm{Wu}(2007)$ found that Shanghai traders could profit from volume induced exuberance.

We find that George and Hwang's result does not hold, either long or short, for a random selection of stocks not in the momentum portfolio. Following an $n$-day high, there is a strong oneday reversal, and returns are insignificantly different than zero thereafter. The returns following an $n$-day low cannot be explained by momentum. Traders should not, we show, short stocks hitting new lows. There are strong, persistent reversals with significant risk adjusted returns on long positions for up to 6 days following an $n$-day low.

The paper is organized into the following sections. Section 2 describes the technical and

${ }^{1}$ Interview in Portfolio, The National Association of Realtors, October/November 2003, available at: http://www.nareit.org/ portfoliomag/03sepoct/capital.shtml 
psychological reasons behind choosing $n$-day high/lows. Section 3 explains our data selections. We model turnover in the fourth section. Persistence of both volume and returns is analyzed in Section 5. Finally, we present our conclusions.

\section{Behavior Behind Technical Analysis}

There are approximately 7,000 stocks in the U.S. equity market. It is a formidable task to analyze them one-by-one to determine which ones to trade. Even institutional brokerage firms do not cover every company. This section reviews the behavioral finance and technical analysis literature that helps motivate our choice of the $n$-day high or low.

\subsection{Investor rules of thumb}

Research in decision theory has helped to explain why investors might use rules of thumb rather than solving a complex dynamic optimization. Kahneman and Tversky (1974) found agents used recent, salient, concrete, and personally relevant information, rather than fundamental values as a basis for their decision making. Ariely, Loewenstein, and Prelec (2003) present experimental evidence that prices paid to avoid painful stimuli depend upon an arbitrary high/low anchor.

The behavioral finance literature has introduced a variety of non-optimizing decision criteria. Studying several large databases with a variety of retail and institutional traders, Barber and Odean (2005) showed that attention is a scarce resource; investors are most likely to trade "attention grabbing" stocks. Prior returns and high turnover are the factors that most strongly influence trading activity. Statman, Thorley and Vorkink (2006) note that overconfidence leads to persistently high trading volume in stocks with high returns.

Studies from experimental stock markets support the importance of specific price levels. Das and Raghubir (2006) find that people perceive local maxima and minima as salient points. They define the run length of a stock as the number of consecutive price changes in the same direction, positive or negative. In their experiments, investors prefer a stock with shorter run length because they perceive it to be less risky. This could potentially explain the absence of a momentum effect at new highs lor lows.

\section{$2.2 \quad$ Survey evidence}

There is not much evidence, even in the practitioner's literature, on what rules technical analysts 
actually use. Menkhoff and Schmidt (2005) report that 36\% of German fund managers they surveyed allocate funds using alternative strategies including technical analysis. A survey by Mizrach and Weerts (2007) of semi-professional traders suggests that simple rules like moving averages $(52 \%)$ and chart patterns $(56 \%)$ are preferred.

\subsection{Technical analysis}

Technical analysis is the use of past price and volume information to predict stock returns. Often, technical analysts are called "chartists" because they employ graphical presentations of their trading rules. Phillips and Todd (2003) find these charts served as landmarks for human perception. They specifically cite local maxima and minima as salient points. In the New York Times, stocks hitting their 52-week highs and lows and those with abnormally high volume are bold faced in the stock page listings.

Highs and lows are also inputs into a number of other technical indicators ${ }^{2}$ including the stochastic oscillator. Let $H_{i, t, n}=\max \left(p_{i, t}, p_{i, t-1}, \ldots, p_{i, t-n}\right)$ be the highest price $p_{t}$ achieved by a stock $i$ during an $n$-day period, and let $L_{i, t, n}=\min \left(p_{i, t}, p_{i, t-1}, \ldots, p_{i, t-n}\right)$ be the corresponding minimum. The stochastic $\% K$ developed by Lane (1983),

$$
\% K=\frac{p_{i, t}-L_{i, t, n}}{H_{i, t, n}-L_{i, t, n}}
$$

and William's (1973) \%R,

$$
\% R=\frac{n H_{i, t, n}-p_{i, t}}{n\left(H_{i, t, n}-L_{i, t, n}\right)}
$$

both rely on $n$-day highs and lows.

Psychological, behavioral, survey and experimental evidence appears to support our choice of simple, widely reported, and graphically oriented rules like the $n$-day high and low. Our empirical analysis proceeds in two steps. We first verify that people trade using these rules by looking at turnover. We then see if returns justify their choices.

\footnotetext{
$\overline{{ }^{2} \text { I rely on www.stockcharts.com }}$ for these definitions, but these are widely utilized indicators in the practitioner literature.
} 


\section{Data Selection}

\subsection{Random sample}

Since the breaching of $n$-day highs or lows is a daily event ${ }^{3}$, we concentrated on the daily frequency, instead of weekly as in Huddart, Lang and Yetman (2007). 1,000 symbols from the NYSE and NASDAQ were randomly selected from all the stocks that traded on the two exchanges between January 1, 1993 to October 31, 2003. 849 stocks were included in the final sample. 151 were discarded due to changes in symbols and not enough data (less than one year trading history during the 10-year period). We had a total of 1,160,951 observations, but since we lose one year of data constructing the 52-week highs, the final sample contains 939, 092 cross-section time series observations.

488 of the listings are from NASDAQ and 361 from the NYSE. They have a $\$ 1.8$ billion market capitalization on average. Their mean length of survival in the sample is 1,106 days, or 4.39 years. Daily trading volume ranges from zero to 814 million shares.

\subsection{Frequency of highs and lows}

As shown in Table 1, 840 of 849 stocks achieved 10-day highs at least once over the ten year span.

[Insert Table 1 Here]

The percentage of stocks that had at least one breakout decreased at 25-day, 50-day, 100-day and 150-day horizons. It troughs at $71.50 \%$ for the 150 -day and then picked up both at 200-day and 52 -week highs, $83.86 \%$.

The percentage for stocks with $n$-day lows showed the same pattern as $n$-day high. On $8.03 \%$ of the overall 939,092 stock trading days, there are breaches of 10-day lows. The percentage went as low as $0.59 \%$ for breaching 150 -day lows. Again, $n$-day lows held the same patterns as $n$-day highs.

\subsection{Turnover}

Lo and Wang (2000) proposed to use the turnover as a canonical measure of trading activity among numerous alternatives, such as total numbers of shared traded $V O L_{i, t}$ or dollar volume,

${ }^{3}$ Huddart, Lang and Yetman (2007) use "the the highest (lowest) daily closing stock price in the 52-week benchmark period ending 20 trading days ... before the last day of the observation week." We did not follow this construction. 
$\$ p_{i, t} \times V O L_{i, t}$. Turnover, $\tau_{i, t}$, scales the daily trading volume by the number of shares outstanding $S O_{i, t}$

$$
\tau_{i, t}=\frac{V O L_{i, t}}{S O_{i, t}}
$$

The advantage of turnover, they argue, is that it not effected by stock splits and dividends.

Table 2 provides a statistical description of daily turnover. The average for our sample was $0.636 \%$, similar to the market's daily turnover of $0.638 \%$.

\section{[INSERT Table 2 Here]}

Daily turnovers are positively skewed. The mean daily turnover of 10-day, 25-day, 50-day, 100-day, 150-day, 200-day and 52-week highs is $0.57 \%, 0.68 \%, 0.82 \%, 0.93 \%, 0.91 \%, 1.16 \%$, and $1.36 \%$. Except for the the 10-day interval, the means of our $n$-day highs are above the sample means of daily turnover. For $n \geq 25$, the turnover is in the $75^{\text {th }}$ percentile, and the 52 -week high is above the $90^{t h}$ percentile. Moreover, these turnovers show a monotonic increase with $n$ except for $n=150$.

The means of daily turnovers on $n$-day lows are relatively smaller than $n$-day highs. They are above the sample means except for the 10-day and 25-day lows. The means on the event days of $n$-day lows are also increasing in $n$ except a drop from 200-day low to 52-week low.

The raw turnovers have a time trend. We render them stationary by regressing them on market turnover $\tau_{M, t}$ as in Ferris, Haugen and Makhiga (1988),

$$
\tau_{i, t}=\rho_{0, i, t,}+\rho_{1, i, t} \tau_{M, t}+\varepsilon_{i, t, \tau}
$$

We take market turnover ${ }^{4}$ to be either the NYSE or NASDAQ measure depending upon where the shares are listed. $\varepsilon_{i, t, \tau}$ is the excess (or abnormal) turnover. Excess turnover on the event days showed almost identical traits as raw turnover.

\subsection{Returns}

We want to control for the effect of returns on turnover. Again, following Lo and Wang, we adjusted our raw returns using the Fama-French (1993) factors and momentum,

$$
A R_{i, t}=\alpha_{i}+\beta_{1, i} R_{M, t}+\beta_{2, i} S M B_{t}+\beta_{3, i} H M L_{t}+\beta_{4, i} M o m_{t}+\varepsilon_{i, t, r} .
$$

\footnotetext{
${ }^{4}$ The trading volumes on NYSE and NASDAQ market are calculated differently due to their different market microstrutures. A trade is counted only once when the NYSE specialist matches a buyer and a seller. A trade is generally double-counted on NASDAQ during our sample. If a buyer sells a trade to a market maker, and he then resells the trade to a seller, NASDAQ will record this as two trades.
} 
$A R_{i, t}$ is the abnormal daily return of stock $i$. It is the daily stock return including dividends $R_{i, t}$ less the risk free rate $R f_{t}$, which we measure as the 1 -month Treasury bill rate. $R_{M, t}$ is the market return. It is the value weighted return on all NYSE, Nasdaq, and AMEX stocks less the risk free rate. The factor $S M B_{t}$ adjusts for market capitalization. It places $1 / 3$ weights on the difference between three small portfolios and three big portfolios consisting of value, neutral and growth stocks. $H M L_{t:}$ is the factor adjusting for value versus growth. It is the average difference of two value and two growth portfolios. These data were all obtained from Ken French's website. ${ }^{5}$

The momentum factor, $\mathrm{Mom}_{t}$, is the daily return difference between an equal weighted portfolio of the high and low return stocks, using the methodology of Carhart (1997) and Barber, Odean and Zhu (2006). The portfolio was constructed to include the stocks with the highest and lowest $30 \%$ of returns in the preceding trading month. $\varepsilon_{i, t, r}$ are excess returns after adjusting for the factors.

\section{Model for Excess Turnover}

We complete the specification of our model for excess turnover by incorporating the additional covariates in Lo and Wang. They include market capitalization, $p_{t} S O_{t}$, volatility, which is measured as the 40-day moving standard deviation, and the stock price level, for which we use the high ask price for the day, $A S K H I_{i, t-1}$. We form a time series cross section. Individual stock fixed effects are handled by taking first differences.

The model then includes seven dummy variables for the $n$-day highs, $D_{i, t, n}^{H}$ and lows, $D_{i, t, n}^{L}$,

$$
\begin{aligned}
\Delta \varepsilon_{i, t, \tau}= & \gamma_{1} \Delta \varepsilon_{i, t, r}+\gamma_{2} \Delta \varepsilon_{i, t-1, r}+\gamma_{3} \Delta \varepsilon_{i, t-1, \tau}+\gamma_{4} \Delta\left(p_{i, t-1} S O_{t-1}\right)+\gamma_{5} \Delta \sigma_{i, t-1}^{2} \\
& +\gamma_{6} \Delta A S K H I_{i, t-1} \sum_{n} \theta_{n}^{H} D_{i, t, n}^{H}+\sum_{n} \theta_{n}^{L} D_{i, t, n}^{L}+\varepsilon_{i, t, T O} .
\end{aligned}
$$

Since 52-week highs are also 200-day highs, etc., we turn on only the indicator with the longest length. If our technical indicators are impacting trading volume, we should find $\theta_{n}^{H}$ and $\theta_{n}^{L}>0$.

Coefficient estimates from (4) with heteroscedastic and autocorrelation consistent (HAC) $t$ ratios are in Table 3.

\section{[Insert Table 3 Here]}

The coefficients on the Lo and Wang controls are all significant. The positive sign on excess returns means that the high return would bring extra trading activity. The significance of lagged excess

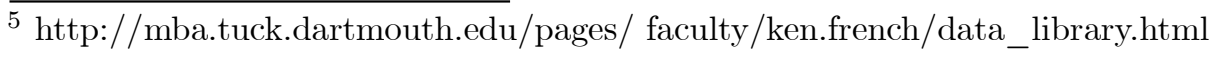


returns and turnover motivates our persistence results in the next section.

The coefficients on the indicator variables of $n$-day highs are all positive and highly significant, and, except for a slight kink at 200-day, are increasing with $n$. We depict this graphically in Figure 1.

\section{[Insert Figure 1 Here]}

The 52 -week high has the largest impact. The $0.3808 \%$ rise in turnover represents an increase of more than $2 / 3$ over the average trading day.

The coefficients of $n$-day lows also increase with $n$, except for a slight drop at the 200-day. This is depicted graphically in Figure 2.

\section{[Insert Figure 2 Here]}

The largest marginal effect is for the 150-day low at $0.3500 \%$. This marginal effect is similar in magnitude to the $n$-day highs despite the fact that there is lower turnover overall when returns are negative.

The results contrast Huddart, Lang and Yetman (2007) who found that trading volume did not spike when prices crossed percentiles of the past price distributions other than the 52-week. Our results show that it is not the past price distribution which affects trading activities but rather the time frame which matters.

Can the effect of $n$-day highs or lows on trading volume simply reflect information flow? We control for major news events with dummy variables for dividends, $D_{i, t}^{D}$, earnings, $D_{i, t}^{E}$, and analyst

recommendations, $D_{i, t}^{A}$.here are 8,981 dividend issues and 14,640 analysts' upgrade /downgrade over 10 years for our sample 849 stocks.

We expanded our basic regression to control for these three events,

$$
\begin{aligned}
\Delta \varepsilon_{i, t, \tau}= & \gamma_{1} \Delta \varepsilon_{i, t, r}+\gamma_{2} \Delta \varepsilon_{i, t-1, r}+\gamma_{3} \Delta \varepsilon_{i, t-1, \tau}+\gamma_{4} \Delta\left(p_{i, t-1} S O_{t-1}\right)+\gamma_{5} \Delta \sigma_{i, t-1}^{2} \\
& +\gamma_{6} \Delta A S K H I_{i, t-1}+\sum_{n} \theta_{n}^{H} D_{i, t, n}^{H}+\sum_{n} \theta_{n}^{L} D_{i, t, n}^{L}+\psi_{1} D_{i, t}^{D}+\psi_{2} D_{i, t}^{E}+\psi_{e} D_{i, t}^{A}+\varepsilon_{i, t, T O} .
\end{aligned}
$$

Table 3 shows the coefficient estimates before and after the news dummies. The extra control variables have little or no impact on estimates or statistical significance of the $n$-day highs and lows. Given that the earnings and recommendations news events are highly significant, we confirm that these are separate phenomena. 


\section{Persistence of Turnover and Returns}

We must consider the possibility that traders rationally enter stocks when they hit $n$-day highs and lows. If trading activity is predictable following these technical signals, it might make sense for traders to either trade long or sell short. We should expect to see some continuation in turnover and returns if this were the case. This section considers both hypotheses.

\subsection{Turnover persistence}

We earlier documented in Table 2 that turnover surges when an $n$-day high or low is achieved. We now look at the 10-day interval following these events,

$$
\left(\varepsilon_{i, t, \tau}, \varepsilon_{i, t+1, \tau}, \ldots, \varepsilon_{i, t+10, \tau}\right) .
$$

Standard errors are the sample standard deviations for event and non-event days.

In Figure 3, we look at turnover persistence for the seven different $n$-day highs.

$$
\text { [Insert Figure } 3 \text { Here] }
$$

Abnormal turnover sharply rises on the event day highs except for the 10-day. For the other six, turnover rises from $7 \%$ for the 25 -day high to $69 \%$ for the 52 -week high. Turnover drifts down

after the event. It is significantly negative for the 10 to 100-day highs after the second day for the full two weeks. While abnormal turnover also falls for the 200-day and 52-week highs, the initial surge is so large, turnover is abnormally positive for six days for the 200-day and all ten days for the 52-week. Abnormal turnover is still $16 \%$ higher two weeks after the 52-week high.

For the $n$-day lows in Figure 4, surges in turnover are less pronounced, consistent with the usual result that bull markets have higher volume. The 50-day to 52-week lows have positive abnormal event turnover, ranging from $6 \%$ for the 50 -day to $26 \%$ for the 150 -day.

$$
\text { [Insert Figure } 4 \text { Here] }
$$

Abnormal turnover then falls after the event day, with the exception of the 10-day low. The 10-day, 50-day, 150-day and 52-week low show significantly negative abnormal turnover for the full two weeks.

We now turn our attention to returns.

\section{$5.2 \quad$ Return persistence}

Raw returns $R_{i, t}$ typically remain positive after the $n$-day highs. This may explain why traders 
make use of the signals. We find that the returns, which are fairly small to begin with, have a negative risk adjusted return, $A R_{i, t}$. We again analyze the ten day period following the event

$$
\left(A R_{i, t}, A R_{i, t+1}, \ldots, A R_{i, t+10}\right)
$$

and compute confidence intervals from the sample of event and non-event days.

$$
\text { [Insert Figure } 5 \text { Here] }
$$

Abnormal returns on the event day highs range from $2.73 \%$ for the 52 -week high to $3.38 \%$ for the 50-day. The momentum factor, as George and Hwang (2004) have noted, explains more of the raw return at the 52-week interval.

There is a significant, negative, one-day abnormal return after an $n$-day high is achieved. This reversal is not particularly large and only slightly exceeds $-0.5 \%$. Abnormal returns are insignificantly different from zero after the second day.

On event day lows, abnormal returns, in Figure 6, range from $-2.29 \%$ for the 10 -day to $-3.74 \%$ for the 52-week.

\section{[Insert Figure 6 Here]}

We find that momentum does not continue after $n$-day lows. Returns reverse, and because the momentum factor looks at these as short opportunities, the risk reward tradeoff is excellent. Abnormal returns for going long after an $n$-day low range from $0.46 \%$ for the 10 -day to $1.15 \%$ for the 52 -week. These risk adjusted returns remain significantly positive for 2 to 10 days for $n>25$.

\section{Conclusion}

When confronting a large amount of information, agents tend to limit their attention to a smaller set of headline facts. In equity analysis, $n$-day highs and lows appear to be salient for traders and investors.

We established a positive relationship between abnormal turnover and the event of breaching both $n$-day highs and lows. Turnover is a positive and increasing function of the time frame $n$, even after controlling for news about earnings, dividends, and analyst recommendations.

Turnover persists after the event day for at least two weeks, positively for the highs and negatively for the lows. Abnormal returns suggest ignoring the trend when $n$-day highs are achieved and being contrarian on the $n$-day lows. 


\section{References}

Ariely, D., G. Loewenstein and D. Prelec, (2000). "Coherent Arbitrariness: Stable Demand Curves Without Stable Preferences," Quarterly Journal of Economics 118, 73-105.

Barber, B. M., and T. Odean (2005), "All that Glitters: The Effect of Attention and News on the Buying Behavior of Individual and Institutional Investors," Working Paper, U.C. Berkeley.

Barber, B. M., T. Odean, and N. Zhu, "Systematic Noise." Working Paper, U.C. Davis, 2006.

Barberis, N, Shleifer A., and R. Vishny (1998), "A Model of Investor Sentiment," Journal of Financial Economics 49, 307-343..

Das, S. and P. Raghubir (2006), "The Long and Short of It: Why are Stocks with Shorter Run-Lengths Preferred?" Working Paper, U.C. Berkeley.

Ferris, S., R. Haugen and A. Makhija (1988), "Predicting Contemporary Volume with Historic Volume at Differential Price Levels: Evidence Supporting the Disposition Effect," Journal of Finance 43, 677-699.

George, T. and C. Hwang (2004), "The 52-Week High and Momentum Investing," Journal of Finance 59, 2145-76.

Heath, C., S. Huddart and M. Lang (1999), "Psychological Factors and Stock Option Exercise," Quarterly Journal of Economics 114, 601-27.

Huddart, S., Lang, M. and M. Yetman (2007), "Psychological Factors, Stock Price Paths, and Trading Volume," Working Paper, Pennsylvania State University.

Kahneman, D. and A. Tversky (1974), "Judgement under Uncertainty: Heuristics and Biases," Science 185, 1124-31.

Lane, G. C. (1984), "Lane's Stochastics," Technical Analysis of Stocks and Commodities 2, $87-90$

Lo, A. and J. Wang (2000), "Trading Volume: Definitions, Data Analysis, and Implications of Portfolio Theory," The Review of Financial Studies 13, No. 2, 257-300.

Menkhoff, L. and U. Schmidt (2005), "The Use of Trading Strategies by Fund Managers: Some First Survey Evidence," University of Hannover, Discussion Paper No. 314.

Mizrach, B. and S. Weerts (2007), "Experts Online: An Analysis of Trading Activity in a Public Internet Chat Room," Rutgers University Working Paper.

Phillips, F. and J. Todd (2003), "Perceptual Representation of Visible Surfaces," Perception and Pschophysics 65, 747-762.

Seasholes, M. and G. Wu (2007), "Predictable Behavior, Profits and Attention," Journal of Empirical Finance 14, 590-610.

Statman, M., S. Thorley, and K. Vorkink (2006), "Investor Overconfidence and Trading Volume," Review of Financial Studies 19, 1531-65.

Williams, L. R. (1973), How I Made One Million Dollars Last Year Trading Commodities, Carmel Valley CA: Conceptual Management. 
Table 1

Frequency of $n$-Day Highs and Low

\begin{tabular}{|l|c|r|r|}
\hline & Variable & \# of stocks & Obs. \\
\hline Highs & & & \\
\hline 10-day & $D_{10}^{H}$ & 840 & 75,367 \\
\hline 25-day & $D_{25}^{H}$ & 811 & 34,211 \\
\hline 50-day & $D_{50}^{H}$ & 769 & 22,942 \\
\hline 100-day & $D_{100}^{H}$ & 688 & 9,710 \\
\hline 150-day & $D_{150}^{H}$ & 607 & 5,554 \\
\hline 200-day & $D_{200}^{H}$ & 641 & 6,014 \\
\hline 52-week & $D_{52 w}^{H}$ & 711 & 40,126 \\
\hline & & & \\
\hline Lows & & & \\
\hline 10-day & $D_{10}^{L}$ & 842 & 83,439 \\
\hline 25-day & $D_{25}^{L}$ & 822 & 29,681 \\
\hline 50-day & $D_{50}^{L}$ & 801 & 26,059 \\
\hline 100-day & $D_{100}^{L}$ & 734 & 10.475 \\
\hline 150-day & $D_{150}^{L}$ & 607 & 5,612 \\
\hline 200-day & $D_{200}^{L}$ & 521 & 3,563 \\
\hline 52-week & $D_{52 w}^{L}$ & 650 & 28,112 \\
\hline
\end{tabular}

The table reports the total number of stocks experiencing the event of an $n$-day high or low. We record the event for the largest $n$. Observations are the number of time-series cross section observations for which the dummy variable takes the value 1 rather than 0 . 
Table 2

Daily Turnover in Percent

\begin{tabular}{|l|r|r|r|r|r|r|l|}
\hline \multicolumn{1}{|c|}{ Sample } & \multicolumn{1}{c|}{ Obs. } & Mean & SD & Skew & Median & $\mathbf{7 5}^{\text {th }}$ & $\mathbf{9 0}^{\text {th }} \%$ \\
\hline Full Sample & 938,499 & 0.6364 & 2.46 & 33.17 & 0.1913 & 0.5204 & 1.2875 \\
\hline & & & & & & & \\
\hline \multicolumn{1}{|c|}{ Highs } & & & & & & & \\
\hline 10-Day & 75,367 & 0.5684 & 1.82 & 14.83 & 0.1740 & 0.4817 & 1.2108 \\
\hline 25-Day & 34,211 & 0.6823 & 3.16 & 64.94 & 0.2117 & 0.5645 & 1.4019 \\
\hline $50-$ Day & 22,942 & 0.8202 & 3.39 & 38.22 & 0.2485 & 0.6679 & 1.6216 \\
\hline 100-Day & 9,710 & 0.9250 & 3.50 & 18.93 & 0.2597 & 0.7526 & 1.9274 \\
\hline 150-Day & 5,554 & 0.9142 & 2.98 & 14.15 & 0.2889 & 0.7539 & 1.9423 \\
\hline 200-Day & 6,014 & 1.1604 & 3.60 & 10.67 & 0.3252 & 0.9126 & 2.3739 \\
\hline 52-Week & 40,126 & 1.3579 & 4.72 & 20.24 & 0.3671 & 1.0970 & 2.9117 \\
\hline & & & & & & & \\
\hline \multicolumn{1}{|c|}{ Lows } & & & & & & & \\
\hline 10-Day & 83,439 & 0.5134 & 1.87 & 18.01 & 0.1591 & 0.4235 & 1.0140 \\
\hline 25-Day & 39,681 & 0.5895 & 2.47 & 31.58 & 0.1712 & 0.4701 & 1.1626 \\
\hline 50-Day & 26,059 & 0.6585 & 2.32 & 15.03 & 0.1795 & 0.5046 & 1.3091 \\
\hline 100-Day & 10,475 & 0.7370 & 3.84 & 55.76 & 0.1926 & 0.5672 & 1.5009 \\
\hline 150-Day & 5,612 & 0.7988 & 3.46 & 20.96 & 0.2067 & 0.6174 & 1.5874 \\
\hline 200-Day & 3,563 & 0.8795 & 3.97 & 22.71 & 0.1987 & 0.6216 & 1.6326 \\
\hline 52-Week & 28,112 & 0.7346 & 3.22 & 44.80 & 0.2190 & 0.6029 & 1.4658 \\
\hline
\end{tabular}

The table reports the daily turnover on days in which the stock achieves an $n$-day high or low. We use the largest $n$ that applies. We study 849 stocks with 939,499 time series cross-section observations. 
Table 3

Model for Abnormal Turnover

\begin{tabular}{lrrrr} 
Regressor & Coeff. & $t$-ratio & Coeff. & $t$-ratio \\
\hline \hline$\Delta$ Abn. Ret $_{t}$ & 0.0235 & 11.96 & 0.0235 & 11.96 \\
$\Delta$ Abn. Ret $_{t-1}$ & 0.0184 & 12.91 & 0.0184 & 12.92 \\
$\Delta$ Abn. Vol $_{t-1}$ & -0.3167 & -16.51 & -0.3172 & -16.52 \\
$\Delta$ Market Cap $_{t-1}$ & -0.4908 & -2.76 & -0.4901 & -2.75 \\
$\Delta$ Volatility $_{t-1}$ & -17.5359 & -4.34 & -17.8969 & -4.41 \\
$\Delta$ High Price $_{t-1}$ & 0.0224 & 2.43 & 0.0225 & 2.43 \\
10-Day High & 0.1332 & 21.13 & 0.1322 & 20.97 \\
25-Day High & 0.1871 & 21.70 & 0.1842 & 21.41 \\
50-Day High & 0.2367 & 21.26 & 0.2339 & 21.05 \\
100-Day High & 0.2760 & 15.35 & 0.2732 & 15.25 \\
150-Day High & 0.3060 & 9.90 & 0.3035 & 9.83 \\
200-Day High & 0.2600 & 11.18 & 0.2579 & 11.12 \\
52-week High & 0.3808 & 30.30 & 0.3779 & 30.14 \\
10-Day Low & 0.1928 & 34.29 & 0.1936 & 34.47 \\
25-Day Low & 0.2496 & 27.94 & 0.2499 & 28.00 \\
50-Day Low & 0.3011 & 27.65 & 0.3002 & 27.64 \\
100-Day Low & 0.3301 & 14.27 & 0.3267 & 14.18 \\
150-Day Low & 0.3500 & 9.05 & 0.3472 & 9.00 \\
200-Day Low & 0.3097 & 10.13 & 0.3079 & 10.12 \\
52-week Low & 0.2376 & 23.38 & 0.2382 & 23.52 \\
Dividends & & & 0.0174 & 1.29 \\
Earnings & & & 0.5395 & 24.97 \\
Analyst Recs & & & 0.3321 & 11.31 \\
\hline $\bar{R}^{2}$ & 0.111 & & 0.112 &
\end{tabular}

The table reports estimates of the model for abnormal turnover (4). The coefficients for market capitalization are $\times 10^{4}$. Heteroscedasticity and autocorrelation consistent $t$-ratios are in the columns next to the coefficient estimates 
Figure 1

Effect of $n$-Day High on Abnormal Turnover \%

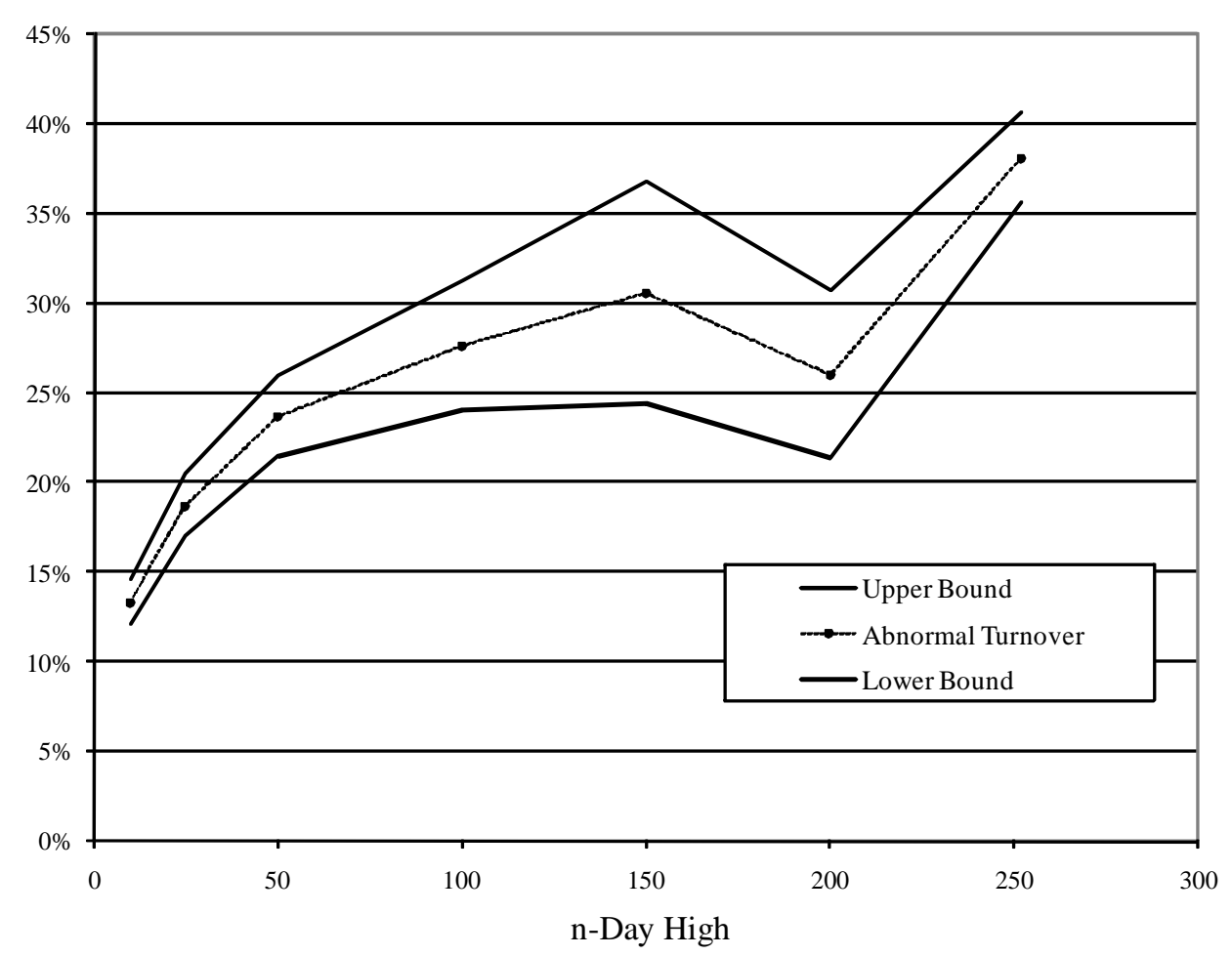

The figure reports percentage effects on abnormal turnover of an $n$-day high event based on estimates from (4). The dark bands are 95\% confidence intervals. 
Figure 2

Effect of $n$-Day Low on Abnormal Turnover \%

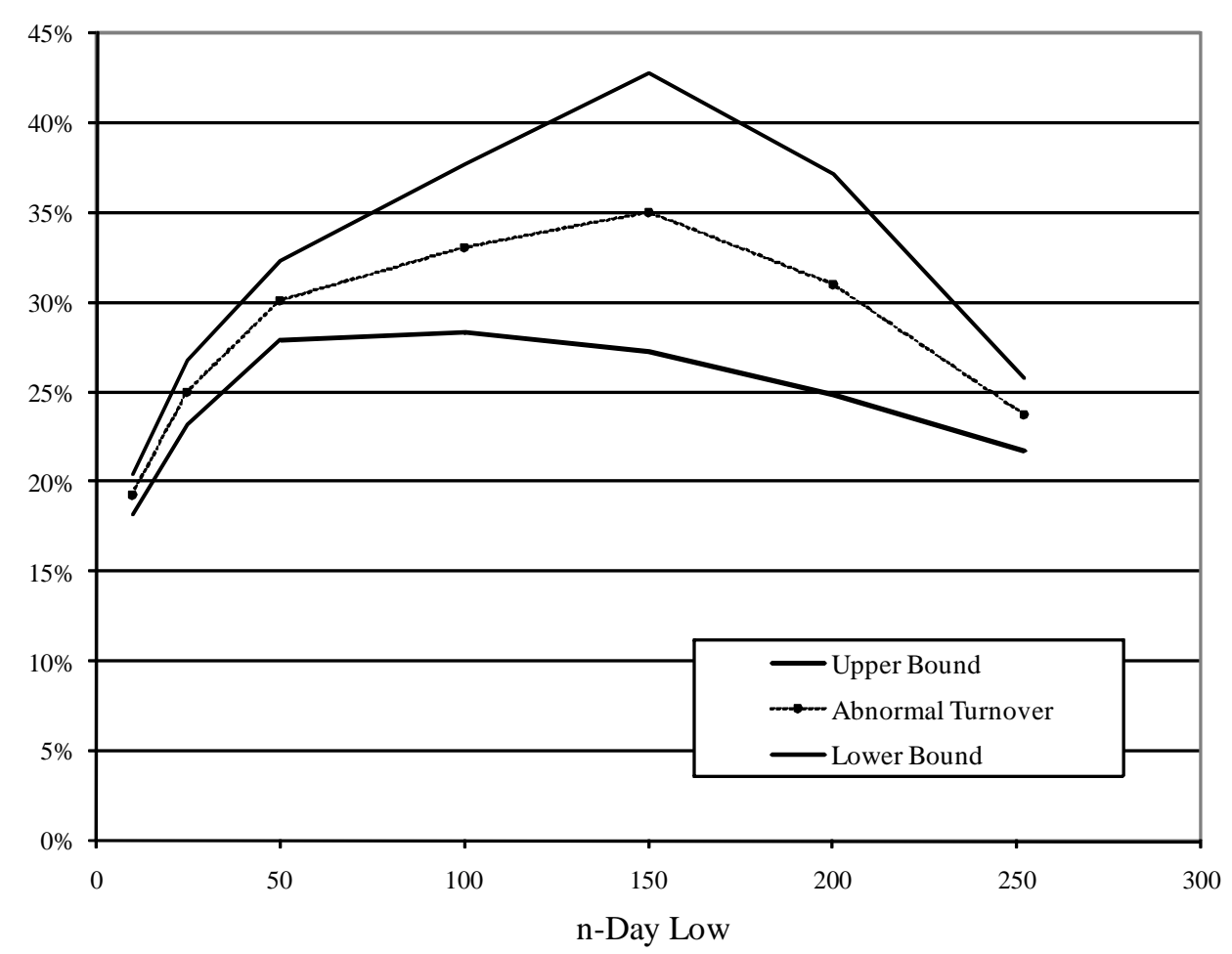

The figure reports percentage effects on abnormal turnover of an $n$-day low event based on estimates from (4). The dark bands are $95 \%$ confidence intervals. 
Figure 3

Turnover Persistence After $n$-Day Highs
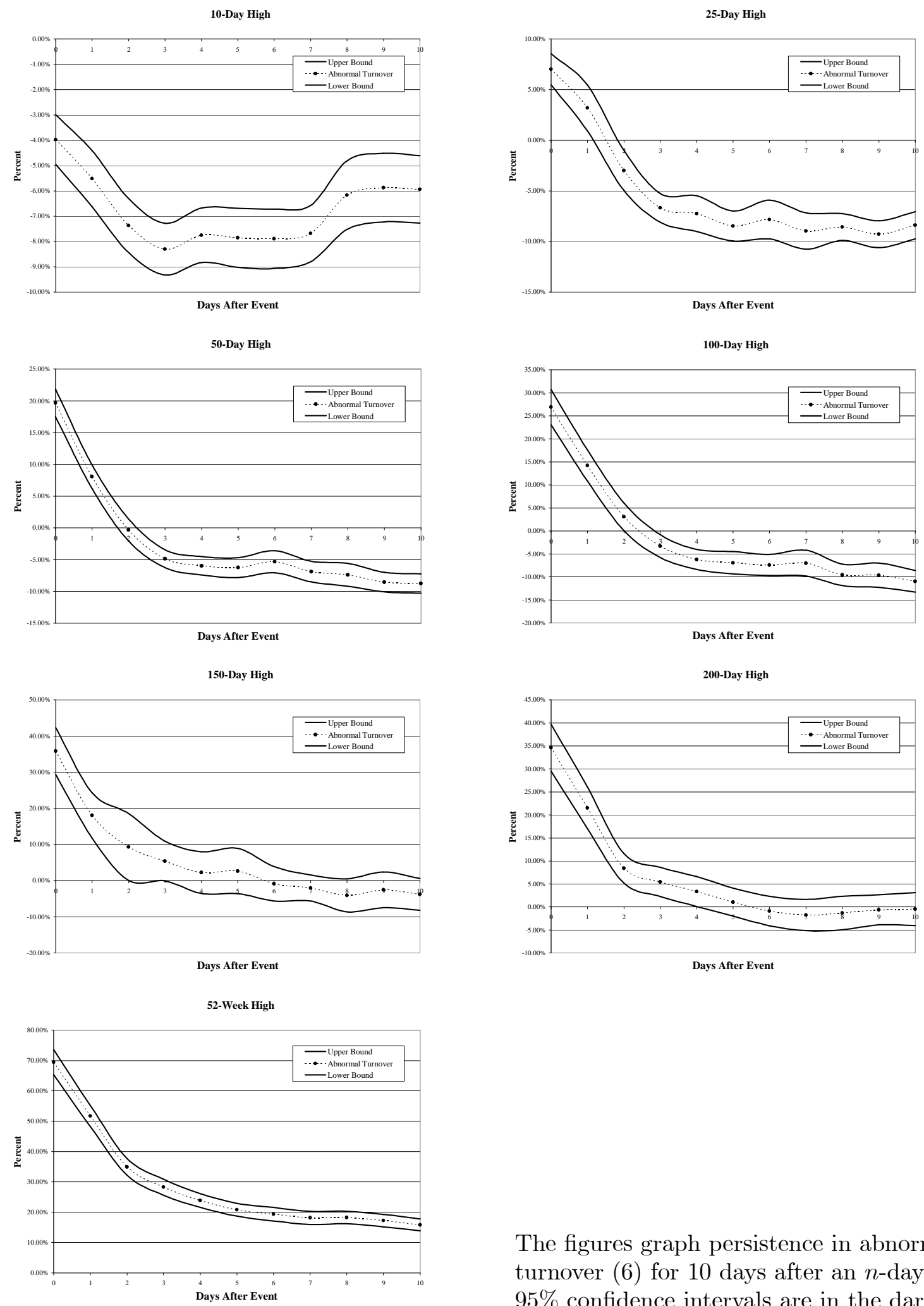

The figures graph persistence in abnormal turnover (6) for 10 days after an $n$-day high. $95 \%$ confidence intervals are in the dark bands. 
Figure 4

Turnover Persistence After $n$-Day Lows
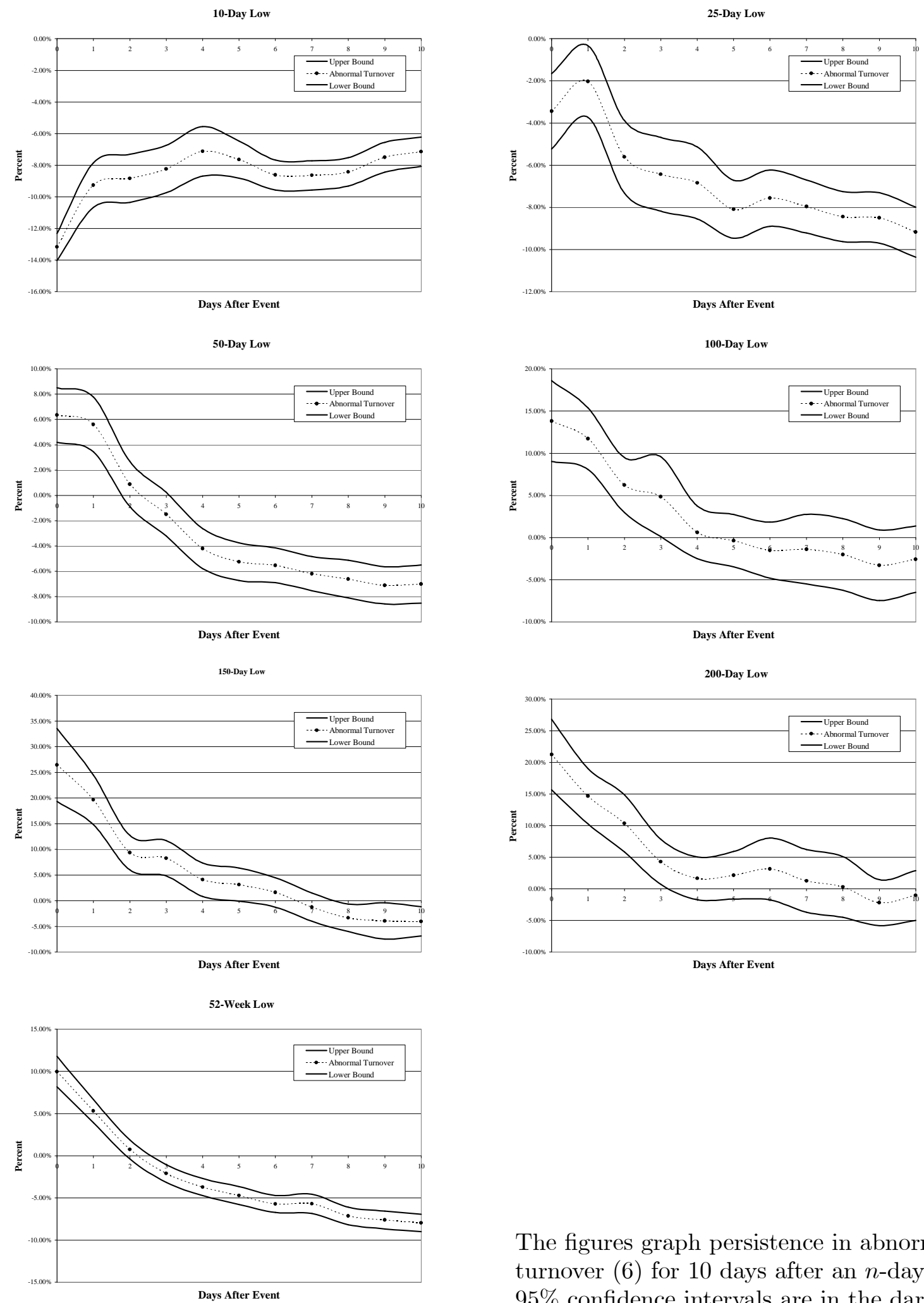

The figures graph persistence in abnormal turnover (6) for 10 days after an $n$-day low. $95 \%$ confidence intervals are in the dark bands. 
Figure 5

\section{Risk Adjusted Returns After n-Day Highs}
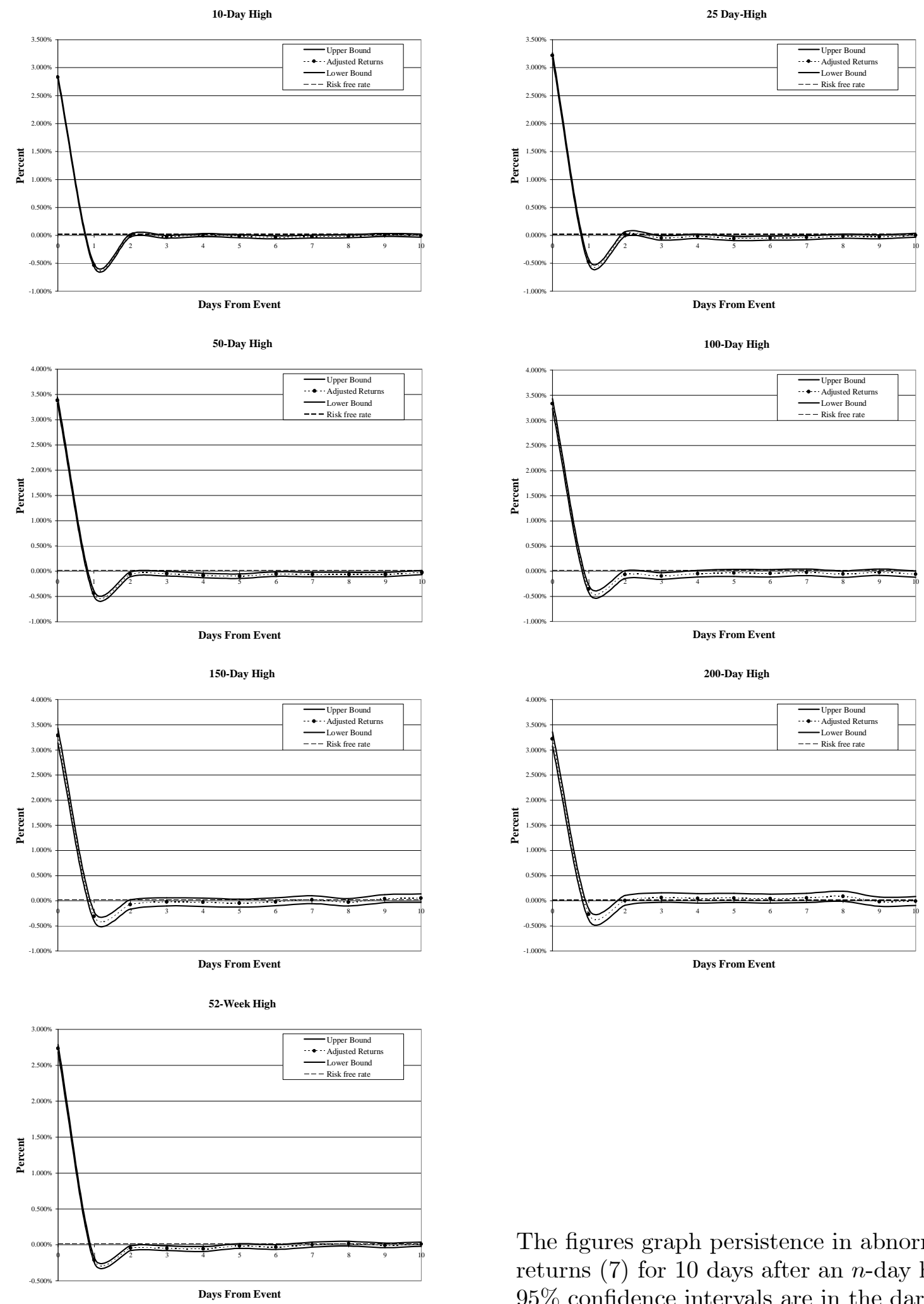

The figures graph persistence in abnormal returns (7) for 10 days after an $n$-day high. $95 \%$ confidence intervals are in the dark bands. 
Figure 6

Risk Adjusted Returns After $n$-Day Lows
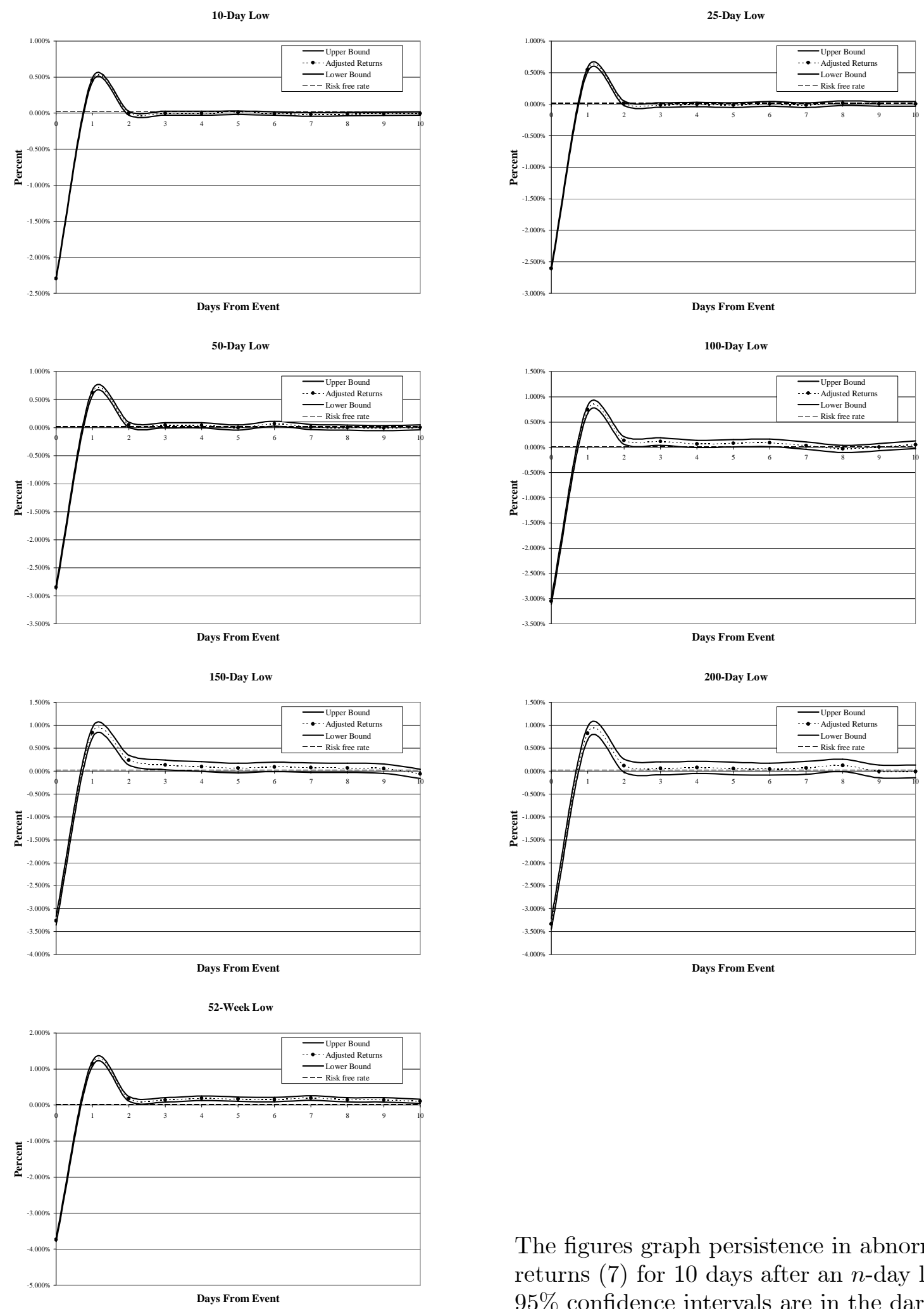

The figures graph persistence in abnormal returns (7) for 10 days after an $n$-day low. $95 \%$ confidence intervals are in the dark bands. 